\title{
The Conceptual Model of Customer Ability to Predominate and Control: Based on the Analysis Framework of Situated Cognition and Learning Theory
}

\author{
Zhang Xiangyu \\ School of Management \\ Wuhan University of Technology \\ Wuhan China \\ e-mail: 390466846@qq.com
}

\author{
Cheng Yanxia \\ School of Management \\ Wuhan University of Technology \\ Wuhan China \\ e-mail: chengyanxia221@126.com
}

\begin{abstract}
Customers for products and services is an important factor in restricting consumer purchase behavior, and developing and nurturing customer ability to predominate and control is a prerequisite for customers to buy the products, as well as capture points of corporate marketing points and resources to accessing core customer. Based on the theoretical derivation of the customer's ability to predominate and control, we analyze the nature of the customer's control, and define the concept of the customer ability to predominate and control, while describes its basic connotation and denotation scientifically, eventually forming the conceptual model of the customer's ability to predominate and control.
\end{abstract}

Keywords- Customer Ability to Predominate and Control; Nature; concept; connotation; conceptual model

\section{INTRODUCTION}

With the transformation from the Service Economy to the Customer Economy, the traditional competition based on technology, products, costs has changed into the customer-centered competition. A survey from an America research firm called Forrester Research shows that, Customer Economy is determined by the customer, "whose needs are to buy better products at a lower price, and to complete their daily business process at a higher level of service." [1] However, with the deepening of technological innovation, more advanced manufacturing technology and brand tools are applied to products and services; The rise of the Internet has largely changed the whole production purchase process, supply chain and the acquisition mode for information, how to buy "better products" that can be operated and used, how to accept the "higher level of service" that customer can enjoy comfortably, has become an important factor restricting customer purchase behavior, pushing buyers and sellers deal reached, and attracting much more attention from business and academic in the Customer Economy Era.

Based on the main idea of customer competence theory, utilizing Situated Cognition and Learning, this paper proposes a concept of competence customer economy era-customer's ability to predominate and control, and tries to build a conceptual model of it based on the analysis of its connotation.

\section{DEFINITION AND CONNOTATION OF SERVICE ENVIRONMENT}

As the core of the research in Western learning theory, Situated Cognition and Learning has been widely utilized to various fields, that is, educational psychology, anthropology, management science and so on. In 1989, Brown, Collins and Duguid in the paper 《Situated Cognition and the Culture of Learning $\rangle$, stated that knowledge and action is mutual, that is knowledge is produced in situations and improved and developed in behaviors $^{[2]}$, while, the customer is a specific transaction subject and its ability to predominate and control products and services is promoted and increased from a series of repeated behavior in purchase situation, like operating, using, enjoying. And it is developed in the dual role of situational and behavioral. From the perspective of situated cognition and learning theory, a theory derived from situational and cognitive behavioral perspectives, and the research ideas about customer's ability to predominate and control come out from it.

\section{A. Customer ability based on situational}

Prahalad and Ramaswamy (2000) ${ }^{[3]}$ first proposed the concept of customer ability, explained that customer ability is "a kind of competitive strength from the customer", that is, the knowledge and skills customer have, the desire to learn and attempt, and the mutual interactive customer actively participate in, all of them is called customer ability.

Du Yumin, Su Huiwen (2001) ${ }^{[4]}$ described that, In the network information situation, customer ability must be fully identified and analyzed, effectively managed and organized in order to establish the core competitiveness to meet individual needs. Yuan Bin, Tang YueJun (2003) ${ }^{[5]}$ indicated that in the situation where enterprises access to resources customer ability is a strategic resource which has a competitive value, summarized four characteristic consists of value, inimitability, scarcity and ductility, as 
well as an evaluation system with seven dimensions including profitability, activity (loyalty), strategic position, reproduction, growth capacity, the capacity for learning, the degree of harmony. Ni Ziyin, Zhang Siqiang, Han Yuqi $(2003)^{[6]}$ in the situation where enterprises innovate probed the main form that customer ability affect product innovation and its management points, and analyzed the effects of customer ability management on innovation advantage, while putting forward about reform measures on adaptability of customer ability management. He Guozheng, Chen Rongqiu ( 2008 ) $^{[7]}$ divided customer ability in new product development into the economic ability, knowledge capability, innovation , cooperation skills, communication skills, according to the definition of customer ability in the new product development situation. Then they pointed out that, there are a variety of customer abilities, but innovation capacity and cooperation skill are taken advantage of in R \& D work, so customers have the ability of this part should participation in the R \& D work.

The authors above defines the concept of customer ability, in different situation from the perspective of the enterprise to manage and take advantage of it. But in the market trade, trading points usually depends on the ability and the willingness of buyers and sellers, while, the customer enjoys mastership in customer economy and they play an increasingly important role in the transaction process. As the Internet era coming, the process of developing the customer ability is affected by information technology situation increasingly obviously, and the customer ability should be defined and analyzed according to the market property of transaction subject and the ownership of transaction initiative in trading behaviors.

\section{B. Consumer Learning behavior based on cognitive learning}

In previous studies on situated cognition and learning, "Situated Cognition" and "Situated Learning" are the two concepts most widely used. In 《MIT Encyclopedia of Cognitive Science》, the author regards situated cognition and learning as a concept to comprehend and apply, and emphasize that individual psychology is often developed in the environment where the cognitive processes are formed, directed and supported. The nature of the cognitive process is determined by the situation, which is the basis of all cognitive activity.

Consumer learning is the key concept of consumer psychology and behavior research. Del.et al. believes that "learning is an indispensable link in the consumption process. In fact, to a large extent, consumer behaviors is learned and developed postnatally [8]". "Most of the information on the goods and services consumers stored in memory are from the learning process (about the brand, what they know, how they think, and how they feel). This information constitutes the basis of their behavior [9]."Chinese researchers Lu Long Bao, Feng Renjiong $(2008)^{[10]}$ considered that consumers learning refers to the activities that consumers purchase and make use of goods, where consumers continue to accumulate knowledge, experience and skills about purchase and consumption, in order to improve the purchase behavior.

Current research on consumer learning theory is mostly focused on the study of consumer learning methods, pathways and subjective and objective factors affecting consumer learning, but in the customer economy, consumer learning is more influenced by situated cognition and learning regular pattern, research on consumer behavior for purchase and consumption in situated cognition and learning theory perspective is still relatively little at present.

\section{CONCEPT AND CONTENT}

\section{A. Concept definition}

In ancient Chinese dictionary, "Drive" refers to adding the saddle bridle, yoke and other harness to the mule, making it easy to ride or servitude; "Control" means to grasp the bridle. "Drive" and "Control" used together, refers to holding the reins while riding forward. Thus, "Driving" implies a clear dominant meaning, and "Control" means a strong control implication, "Predominate and Control" is a verb expressing grasp, control and domination, "Ability to Predominate and Control" is represented the level of grasping, the effect of dominant and the degree of control. If the subject implementing controlling, driving and guiding is defined as a natural person, "ability to predominate and control" is to describe people's ability to grasp, dominant and control, it is a reflection of people master knowledge and operate skills.

Customer ability to predominate and control is a situated concept of competence and capacity in customer economy. With the arrival of customer economy, the market situation is becoming more diversified and complicated, as the main subject in market transactionscustomer, purchasing and making use of product are more affected by the purchase situation, and in different situations customers will make extremely different purchasing decisions and behavior. This paper defines the concept of customer ability to predominate and control on the basis of the core idea about customer ability, and will focus on the effect of main subject in market transactions and the influence of different situations.

Customer ability to predominate and control refers to a ability that in the market transactions situation, the customer can flexibly operate, free control, correctly implement, and fully enjoy the product or service, by positively learn or subtly environmental influences, based on plenty understanding the function, performance, structure, principles, operating procedures and usage conditions of the product or service, in order to use, regale on even enjoy it.

\section{B. Content Analysis}

1) The actuation force of Customer ability to predominate and control generation is customer demand.

Customer ability to predominate and control is an ability formed consciously or unconsciously, driven by customer needs, in order to use, regale on even enjoy the value of goods or services provided by enterprises. And, the upgrade expectations and changing needs of customer are the root causes, which keep the customer continuous learning, accumulating and improving knowledge and skills about products and services, and then the customer acquires the ability to predominate and control. 
2) The formative foundation of customer ability to predominate and control is positively learn and subtly environmental influences.

Customer ability to predominate and control is a specialized customer ability in the market transactions situation, including both the subtly imperceptible influence of the market transactions and purchase situation, and the active learning to use the product or service. In the process of building the market transactions and purchase situation, enterprises enjoy mastership.

3) Reserve, accumulation and gradualism are 3 characteristics of customer ability to predominate and control.

Customer ability to predominate and control cannot accomplish in an action, promoted and enhanced from the continuous accumulation of the knowledge and experience, after customer recurrent purchase and usage behaviors. During the customer's acquisition process of this ability, the degree to predominate and control product or service is gradually increased, likely to show vary from a rusty initial operation to a skilled operation, and then the fully flexible control, which is a gradual process.

4) Enterprise plays a boosting role in the formation and development of customer ability to predominate and control

The strength of customer ability to predominate and control plays a vital role in trading points. Smart companies should try to use a variety of resources to help customers improve and enhance the ability to predominate and control, in order to achieve business goal. By developing the customer ability to predominate and control, and by exploiting the trading points, it can form and improve the company core competence. In order to get more trading opportunities, enterprises should create an appropriate transaction situation and a proper usage context, and cultivate customer ability to predominate and control. Furthermore, enterprises could guide customers to purchase and inform customers product information comprehensively and systematically, to improve customer ability to predominate and control.

\section{Extension Analysis}

Customer predominate and control behavior usually occurs during trading activities, which is an important factor to exploit the market potential and find trading opportunities point. With the depth study on customer ability to predominate and control, this paper argues that the acquisition process of it not only limited by customer' own experience, but also by the impact of enterprises behavior. In the extension study, this paper will focus on extending the study to the enterprise level, that enterprises play a vital role in cultivating customer ability to predominate and control. The cultivation process is the key to the discovery of trading opportunity points and the formation of core competitiveness.

1) Aiming at more trading opportunity points, enterprises should create an appropriate transaction situation and a proper usage context to cultivate customer ability to predominate and control.

In the corporate marketing activities, continuous attention to cultivating customer ability to predominate and control, projecting appropriate transaction situation and proper usage context, to stimulate consumer purchasing behavior by subtly imperceptible influences. Sun Yongjun (2012) ${ }^{[11]}$ suggested that the experience factors affecting consumer learning in the study, included firsthand experiences and others experiences. Firsthand experiences refers to consumers grasp the various situations about consumption patterns, consumer objects directly by participating in consumption practices, to improve their consumer behavior. Others experiences refers to consumers grasp a variety of consumer issues from the knowledge and experience of others, or a commercial source of information indirectly, to guide their own consumer behavior.

2) Aiming at product differentiation, enterprises should synthetically consider a variety of the factors affecting product designing, to help customers accomplish predominate and control behaviors.

In knowledge economy era, to make the right consumption decisions in accordance with their own needs, consumers tend to collect and collate all relevant information about product, which is assessed and analyze through consumers own judgement, when facing numerous complex products. Inspired by customer ability to predominate and control, when design and manufacture the products, enterprise should synthetically consider the situations where customers use, regale on, even enjoy the products or services, minimizing the unfavorable factors farthest, to help customers cognize and better use of products or services.

3) Aiming at enhancing the core competitiveness, enterprises should educate and guide customers to purchase, informing product information comprehensively, systematically, skillfully and repeatedly, to help customers improve the ability to predominate and control.

In market development and promotion, enterprises should inform customers product information clearly, comprehensively, systematically, skillfully and repeatedly, promoting customer awareness of the product and achieving the purpose of education and guidance. Bai Changhong, Liao Wei (2001) ${ }^{[12]}$ consider that when designing, producing, and providing value for customers, enterprises should proceed from the customer-oriented, regard the perception of customer for value as a deciding factor. The extension of customer ability to predominate and control further proof that, in trading activities, the customer is the predominating and controlling subject with greater autonomy. Only customer-centric and on the basis of meeting customers' needs can enterprises enhance the customer this ability, by repeatedly telling, educating and guiding so as to effectively exploit the market opportunities.

\section{CONCEPTUAL MODEL}

Lu Changbao, Feng Renjiong (2008) ${ }^{[10]}$ argues that consumer learning is the behavior under the effect of the stimulation from goods and ads, which people cannot assess directly. Thus, the degree of learning can be measured through consumer behavior and knowledge. In view of the above, customer ability to predominate and control can be divided into different dimensions and hierarchies according to different levels of control. 


\section{A. Dimension Division}

By division situation, cognitive processes, cognitive activity 3 dimensions, the dimensional analysis of customer ability to predominate and control is discussed.

\section{1) Situation Dimension}

The nature of the cognitive process is determined by the situation, the situation is the basis of all cognitive activity. According to product hierarchy theory, in terms of different acquisition situations, this paper will divide customer ability to predominate and control acquisition situations into three kinds:

One is usage, that is, maximize the use of core product and form product, as a way to show the customer satisfaction of needs in a certain extent;

One is regaled with the products or services, that is, make full use of and regale on expected product, this stage shows that the spirit of joy and pleasure after meeting the demand;

The other is enjoy, that is, fully recognize and actively enjoy extended (additional) products and potential products, the specific performance is to give consumers a higher level of expectations and value pursuit.

\section{2) Cognitive Process Dimension}

The cognitive process of customer acquiring this ability, experiences from firstly learning about the product or service, gradually knowing well it to fully mastering it. For example, after buying a car, consumers need to understand the basic performance of the car, learn about the construction of the car and related traffic laws, then be familiar with driving, maintenance and repair and other techniques, at last fully master the driving and operating.

\section{3) Cognitive Activity Dimension}

It is to the object that the subject for whom this dimension is discussed. Awareness of the product or service is also divided into different stages, including learning about the product function, performance, structure, working principle or operation processes, grasping the application methods and operating skills, and the highest level for cognitive activity is to proper usage, flexible operating and free control. Also in the car driving, for example, in terms of cognitive content, the customer first masters the basic performance, construction and working principle of the car, then grasp the basic driving skills, and finally could properly perform, flexibly operate, and free control, that is called "harmony between the car and human".

\section{B. Hierarchical Division}

According to content analysis, the subject of customer ability to predominate and control is the customer, the object is the product or service.

Philip Kotler (1976) proposed a three-tier product theory (Core products, Form Product and Extra Product), and a four-level theory (core product, facilitating product, supporting products, argument product) and a five level theory improved and amended finally. This paper presents customer ability to predominate and control is divided into three levels, that is:

- Ability to use: it is the acquisition process to that the customer predominates and controls the core value or the general products, to solve some problems and meet the specific needs.
- Ability to regale: it is a series of activities that gives consumers a higher level of expectations and value pursuit.

- Ability to enjoy: it is the pursuit of a higher level of demand for higher expectations and values.

\section{Conceptual Model}

Based on the concept and content, combined with the above analysis of dimensions and hierarchies, according to the degree of predominates and control, the paper tries to build a conceptual model shown in Figure 1.

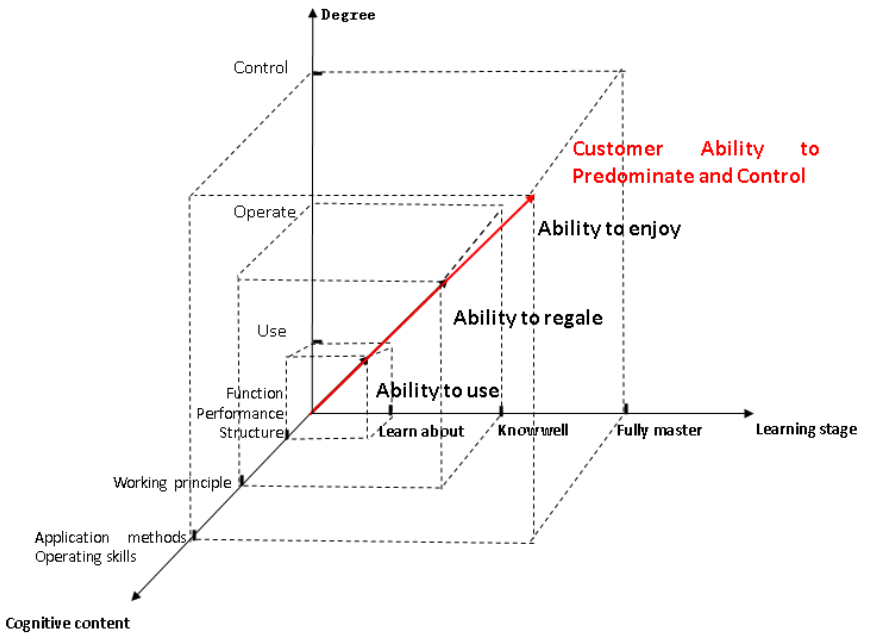

Figure 1. Conceptual Model

\section{CONCLUSION}

In the Internet environment with the rapid development of technology, the replacement rate of the product or service have gone beyond the operational capability and intelligence level of most customers, so customer ability to predominate and control directly affects the customer make purchasing decisions.

Based on Situated Cognition and Learning Theory, the paper proposed the concept of customer ability to predominate and control, and analyzed its content from the driving force, formation basis, basic attribute and subject and object 4 perspectives; According to the definition of concept, analysis of connotation and denotation, customer ability to predominate and control is divided into the situation, cognitive processes and cognitive activity three dimensions; In terms of Product Hierarchy Theory, it includes ability to enjoy, ability to regale and ability to enjoy; Finally, combined with the analysis about dimensions and hierarchies, the paper has built a threedimensional conceptual model using degree of predominate and control, learning stage, cognitive content information system of product or service as coordinates.

\section{REFERENCES}

[1] He Xun. Brand 3Vs strategic in Customer Economy Era [J].Chinese Brand, 2007,(07):88-90.

[2] Wang Wenjing. Review on Situated Cognition and Learning Theory [J].Global Education, 2002,(1):51-55.

[3] C.K.Prahalad and Venkatram Ramaswamy, Co-opting Customer Competence[J].Harvard Business Review, 2000(Jan-Feb).

[4] Du Yumin, Su Huiwen. the Customer Ability to manage on Network Information Environment [J]. Foreign Economics and Management, 2001,23(11):17-20. 
[5] Yuan Bin, Tang Yuejun. Capacity Evaluation Index System Based on Resource View customer $[\mathrm{J}]$. Contemporary Finance \& Economics, 2003,(11):67-70.

[6] Ni Ziyin, Zhang Siqiang, Han Yuqi. Management of Customer Competence Based on Product Innovation and Its Competitive Advantages [J]. Science and Science Management, 2005,(10):66-70.

[7] He Guozheng, Chen Rongqiu. New product development capability of customer value Sort [J].Statistics and Decision, 2008,(4):187-188.

[8] Hawkins, Best, Coney. Consumer Behavior [M]. Beijing: Mechanical Industry Press, 2000.

[9] Jianglin. Consumer Psychology and Behavior (third edition)) [M]. Beijing: China Renmin University Press, 2007.

[10] Long Bao Lu, Feng Renjiong. Application consumer learning theory and outlook in the field of marketing $[\mathrm{J}]$. Fuzhou University (Philosophy and Social Sciences), 2008,(1):14-19.
[11] Sun Yongjun. Factors affecting consumer Learning [J]. New West, 2012,(17):73-79.

[12] Bai Changhong, Liao Wei. Perceived customer value based on customer satisfaction study [J]. Nankai Journal, 2001,(6):14-20.

[13] Seybold, Patricia B., Marshak, Ronni T. and Jeffrey M. Lewis, The Customer Revolution: How to Thrive When Customers Are in Control[J].New York : Crown Publishing Group, March 2001.

[14] Shi Tao, Wang Yang. Study based on market timing detection method innovative customer consumption data [J]. Soft Science,2015, 183(03):125-129.

[15] Zhao Jiang, Mei Shu'e, Zhong Weijun. Delivery based on dynamic targeted advertising different strategic consumer behavior [J]. Soft Science, 2015, 183(03):115-119 